\title{
Achievement Goals and Sportspersonship Orientations in Team Sports. The Moderating Role of Demographic Characteristics
}

\author{
Vassilis Barkoukis (Aristotle University of Thessaloniki) \\ Katerina Mouratidou (Aristotle University of Thessaloniki)
}

\section{Introduction}

Morality is synonymous with the concepts of "good" and "bad" and/or of "right" and "wrong" Arnold $(1994,76)$ claimed that the term morality "involves a consideration of and concern for others as well as for ourselves". Besides that, Shields and Bredemeier (1995, 192-193) associated morality with the term of character. More specifically, they defined character "as the possession of those personal qualities or virtues that facilitate the consistent display of moral action" and described it according to four virtues: (a) compassion, (b) fairness, (c) sportspersonship, and (d) integrity.

Sportspersonship represents a multifaceted construct. Among the most prominent theories for the interpretation of the term sportspersonship is the social-psychological approach (Vallerand et al. 1997; Vallerand \& Losier 1994). According to this sportspersonship concerns five dimensions of behavior in sport: (a) full commitment toward sport participation, (b) respect for social conventions, (c) respect and concern for the rules and officials, (d) respect and concern for the opponent, and (e) negative approach toward the practice of sport.

\section{Achievement Goal Theory}

Elliot and McGregor (2001), based on the dichotomous approach (Nicholls 1989), developed the $2 \times 2$ achievement goal approach by incorporating the approach and avoidance distinction. The $2 \times 2$ achievement goal approach includes four achievement goals: (a) a mastery-approach goal focusing on personal improvement and task mastery, (b) a mastery-avoidance goals reflecting an individual's focus on avoiding a lack of improvement, (c) a performance-approach goal representing the engagement in an activity striving to show higher competence relative to other participants, and (d) a performance-avoidance goal focusing on avoiding the demonstration of low competence compared to other participants. Research in sport and physical 
education indicated that mastery-approach goals have a more positive pattern of cognitive, affective, and behavioral responses relative to performanceapproach goals, which have a more positive pattern compared to performanceavoidance goals (Cury et al. 2003). In addition, research evidence suggested that mastery-avoidance goals have a more negative pattern of responses in education compared to mastery-approach goals, but a more positive one compared to performance-avoidance goals (Cury et al. 2006; Elliot \& McGregor, 2001). Yet, so far research examining this approach in sport is limited (Conroy et al. 2003).

\section{Achievement Goals, Demographic Characteristics And Sportspersonship Orientations}

Research examining the association between sportspersonship and achievement goal orientations suggests that: (a) high task-orientation is positively correlated with sportspersonship orientations (Lemyre et al. 2002), (b) high ego orientation is positively associated with a reduction in sportspersonship orientations (Lemyre et al. 2002), unsportmanlike play, and cheating (Duda et al. 1991), (c) ego-oriented athletes tend to accept more intentionally injurious acts against one's opponent (Duda et al. 1991), (d) compared to ego-oriented, task-oriented players displayed higher prosocial choice (Sage \& Kavussanu 2007), and (e) task orientation was a positive predictor of respect for opponents and respect for the game (Gano-Overway et al. 2005). In addition, other relevant studies evidenced that participation in competitions correlates negatively with sportspersonship orientations (Vallerand, Losier 1994), and educational programs for children with special needs, such as "Fair Play for Kids", could promote morality (Gibbons et al. 1995).

Prior research evidence was based on the dichotomous approach of achievement goals. However, there is only limited evidence associating the $2 \times 2$ approach with morality. Specifically, Corrion et al. (2010) conducted a study in a physical education setting and found that both performance goals (e.g., performance-approach and performance-avoidance goals) mediated the relationships between entity perceptions of ability (i.e., a belief that one's ability is fixed) and the judgment of cheating acceptability, whereas both mastery goals (e.g., mastery-approach and mastery-avoidance goals) mediated the relationships between incremental perceptions of ability (i.e., a belief that one's ability is malleable) and the judgment of cheating acceptability. In addition they found that mastery goals (approach and avoidance) were negative predictors of judgment of cheating acceptability, and performance goals (approach and avoidance) positive ones.

Another important line of research examined the role of several demographic athlete characteristics, such as gender, years of experience, level 
of sport participation (amateur or professional), perceived ability, and age in the development of morality in sport (Mouratidou et al. 2012). Findings concerning the relationship between athletes' gender and their moral competence have been mixed. On one hand, several studies indicated gender differences in the aspects of morality with males demonstrating lower levels of moral judgment, intention, and behavior and higher levels of unsportspersonship behaviors and legitimating more aggressive and intentionally injurious acts in sports compared to females (Gardner \& Jannelle 2002; Kavussanu \& Roberts, 2001; Shields et al., 2007). On the other hand, other studies did not find gender differences in the aforementioned aspects of morality (Fry \& Newton 2003; Guivernau \& Duda 2002; Karamavrou et al. 2004). These controversial results could be possibly attributed to differences in the investigation settings and in the age of the participants. Most of the first group of studies suggesting gender differences in morality were conducted in a sport environment with adult athletes. Corrion et al. (2010) and Gardner and Janelle (2002) reported that aggressive behavior in sport is more socially acceptable for males than for females, as sport is a powerful determinant in the socialization of males. On the other hand, the studies reporting lack of gender differences were conducted in an educational environment (e.g., physical education, and high school sports), with children and/or adolescents, due to lower competition and different socializing processes as compared to competitive sport.

As far as years of experience are concerned, research indicated that the more experienced athletes, particularly males, approve illegitimate and accept more aggressive acts (Gardner \& Janelle 2002). In general, years of sport participation correlate negatively with sportsmanship behavior (Blair 1985). With respect to the level of competition, research indicated that as the level of sport participation increases, less emphasis is being placed on playing fairly and on athletes' moral competence (Mouratidou et al. 2007), and that aggressive sport behavior is perceived as more legitimate (Corrion et al. 2010). Accordingly, as competition standards increase, sportspersonship declines, while aggressive play becomes more acceptable and rule violation increases (Treasure et al. 2000). Regarding age, research showed that older, compared to younger, athletes display lower prosocial and higher antisocial behaviors (Kavussanu et al. 2006; Shields et al. 2007).

\section{The Present Study}

Based on literature reviewed, it seems that there is substantial evidence linking the dichotomous approach of achievement goals with sportspersonship orientations. Previous research utilizing the 2x2 approach indicated that the four goals have a differential effect on several psychological constructs in competitive sport (Conroy et al. 2003; Cury et al. 2006). To the 
best of our knowledge, to date there is no evidence on the effect of the four achievement goals on sportspersonship orientations in competitive sports. In a physical education context a pattern similar to the dichotomous approach was found; both mastery goals showed a negative and both performance goals a positive association with students' judgment of cheating acceptability (Corrion et al. 2010). Corrion et al. urged for more research investigating the effect of the four achievement goals on moral-related variables in sporting contexts. Clearly, a more thorough investigation of the effect of the four achievement goals on sportspershonhsip orientations is needed to gain a more comprehensive understanding of the influence of dispositional achievement goals on the development of moral-related variables in sport settings.

Hence, a basic objective of the study was to examine the effect of the four achievement goals on sportspersonship in a competitive sport context. Based on previous research we hypothesized that mastery-approach goals will be positive predictors of sportspersonship orientations, whereas masteryavoidance and performance goals (approach and avoidance) negative ones. With respect to performance goals, performance-avoidance goals were hypothesized to have a stronger negative effect on sportspersonship orientations compared to performance-approach goals.

With respect to demographic characteristics, research so far has shown clear associations between certain characteristics, such as gender, experience, and level of participation, with sportspersonship. Yet, there is no evidence on whether such characteristics interact with achievement goals to influence sportspersonship orientations. Mouratidou et al. (2012) indicated that athletes' age, experience, and level of sport participation, moderated the relationship between ones' achievement goals and their moral competence. Hence, it was expected that athletes' demographic characteristics would influence the effect of achievement goals on another relevant to morality concept such as sportspersonship orientations. Therefore, a secondary objective of the study was to examine whether demographic characteristics, such as age, gender, level of education, years of sport experience, level (amateur vs professional) and league of competition, athlete's position (defense, center, and offence), and occupation moderate the effect of the achievement goals on the five aspects of sportspersonship. Based on previous research on the moderating effect of these demographic characteristics on moral competence (Mouratidou et al. 2012; Shields et al. 2007) we hypothesized that age, years of experience, gender, and level and league of sport participation, would moderate the achievement goal-sportspersonship relationship. Younger and less experienced athletes, females, and athletes participating in amateur leagues were expected to have the most positive sportspersonship orientations pattern. No significant moderating effect was expected for the level of education and occupation. Finally, given the absence of a validated in Greek instrument to measure sportspersonship orientations, 
another purpose of the study was to test the factorial validity and reliability of the Multidimensional Sportspersonship Orientation Scale (MSOS; Vallerand et al. 1997).

\section{Method}

\subsection{Sample}

The sample of the study was comprised of 407 Greek team sport athletes, with a mean age of 20.47 years $(S D=5.37)$. One hundred and twenty-eight of the participants were football players, 80 were basketball players, 99 were handball players and the remaining 100 were volleyball players. Athletes were recruited from teams participating in the national and local leagues.

\subsection{Measures}

Demographic characteristics. Based on the aforementioned literature, a number of demographic characteristics were included. More specifically, athletes were asked to report their age, gender, level of education $(1=$ elementary, 2 = high school, 3 = university, and $4=$ post graduate studies), level of sport participation ( $1=$ professional vs $2=$ amateur $)$, the league they were competing, years of experience, their occupation $(1=$ public servant, $2=$ selfemployed, 3 = private servant , and $4=$ unemployed .

Achievement goals. The four achievement goals proposed by the $2 \times 2$ achievement goal approach were measured via the $2 \times 2$ Achievement Goals Questionnaire for Sport (AGQ-S; Conroy et al. 2003). AGQ-S is an adapted version of the original Achievement Goals Questionnaire (Elliot \& McGregor 2001) for sport settings. The questionnaire consists of 12 items; three per subscale: (a) mastery-approach (e.g., "It is important to me to perform as well as I possibly can"), (b) mastery-avoidance (e.g., "I worry that I may not perform as well as I possibly can"), (c) performance-approach (e.g., "It is important to me to do well compared to others"), and (d) performanceavoidance (e.g., "My goal is to avoid performing worse than everyone else"). Responses were anchored on a 7-point Likert scale ranging from not at all true of me (1) to very true of me (7). Conroy et al. (2003) have provided evidence on the psychometric properties of the questionnaire. Mouratidou et al. (2012) also supported the four factor structure of the questionnaire with Greek athletes $(C F I=.96, R M S E A=.058)$ and the internal consistency of the factors $(\alpha>$.72).

Sportspersonship orientations. The Multidimensional Sportspersonship Orientation Scale (MSOS; Vallerand et al. 1997) was used to assess athletes' sportspersonship orientation. The MSOS consists of 25 items comprising five subscales designed to estimate sportspersonship orientations: (a) respect for social conventions of sport (e.g., "I shake the opponent's hand after a game 
regardless if we have lost or won"), (b) respect for rules and officials (e.g., "I respect the rules"), (c) respect and concern for the opponent (e.g., "When an opponent gets hurt, I ask the official to stop the game so that he/she can be helped"), (d) respect for one's commitment toward participation in sport (e.g., "It is very important for me to be at every practice"), and (e) negative approach toward the practice of sport (e.g., "After competition, I make excuses for a poor performance"). Although the negative approach toward the practice of sport subscale showed low reliability in previous studies (e.g., Lemyre et al. 2002), it was included in the present study in order to test the original scale's psychometric properties. All subscales consisted of five items. Responses were anchored on a 7-point Likert scale from does not correspond to me at all (1) to corresponds exactly to me (7). Based on Vallerand and Losier (1994) recommendations, a sportspersonship orientations index was calculated by averaging the scores of the subscales produced in the final version of the scale.

\subsection{Procedure}

The design of the study was in accordance with the Code of Ethics in Research of the Aristotle University of Thessaloniki. The aim of the study was described and permission was obtained from sport clubs' managers and coaches. Athletes were informed about the objectives of the study and gave consent to participate in the study. All athletes agreed to participate and completed the questionnaires before or after practice in a quiet environment (e.g., dressing room) and under the researchers' supervision. The coaches of the athletes were not present, while two of the investigators remained during the completion to help with any questions or problems that arose. The researchers clarified to all participants that the questionnaires did not evaluate their progress in sport and that there were no right or wrong answers, and asked participants to work individually. In addition, the athletes were assured that their responses were confidential and anonymous. The questionnaires took approximately 15 to 20 minutes to complete and no difficulties emerged as far as answering the items.

\subsection{Data analysis}

Confirmatory factor analysis (CFA) was used in order to test the factorial validity of the Multidimensional Sportspersonship Orientation Scale. CFA was conducted via EQS, 6.1 structural equation modeling computer program (Bentler 2004). The comparative fit index (CFI) was used as a focal index of goodness-of-fit, as it has a standardized 0-1 range, small sample variability, and stability with various sample sizes (Bentler 2004). The Comparative Fit Index (CFI) and Root Mean Square Error of Approximation (RMSEA) were used as more appropriate indices to evaluate the adequacy of models as they are not influenced by sample size. A cut-off value of .90 or above for the CFI is typically considered an acceptable criterion for model fit, although a value 
greater than .95 shows excellent fit (Hu \& Bentler 1999). A cut-off value of .08 or below for the RMSEA was considered appropriate for satisfactory model fit (Hu \& Bentler 1999).

Moderated hierarchical regression analyses were used to examine the effect of achievement goals on sportspersonship orientations, and whether the demographic characteristics moderate the achievement goalssportspersonship orientations relationships. To test for moderation effects (a) both predictors and moderators should be mean centered, (b) predictors should have a unique effect on the dependent variable, (c) an interaction effect should be computed between each predictor and each moderator, and (d) a significant effect of the interaction effect on the dependent variable should emerge (Frazier et al. 2004).

\section{Results}

\subsection{Preliminary statistics}

Means, standard deviations and Cronbach alphas for the study's variables are shown in Table 1. Two hundred and sixty one of the athletes were males (Mage $=21.44, S D=5.21)$, and 146 were females (Mage $=18.73, S D=5.23)$. One hundred and twenty five of the participants were 12-17 years old, 196 were 18-23 years old, 60 were 24-29 years old, 17 were 30-35 years old and nine were $36-45$ years old; overall $69.3 \%$ of the participants were older than 17 years old. Thirty one of the participants (7.6\% of the athletes) were primary school graduates, 321 (78.8\% of the athletes) graduated from high school and the remaining 55 athletes ( $13.5 \%$ of the sample) had a university degree.

\begin{tabular}{lccccc}
\hline & Mean & SD & $\begin{array}{c}\text { Skewnes } \\
\text { s }\end{array}$ & Kurtosis & $\begin{array}{c}\text { Cronbac } \\
\mathbf{h} \boldsymbol{\alpha}\end{array}$ \\
& & & & & \\
\hline Mastery-approach & 6.03 & 1.26 & -1.920 & 1.208 & .85 \\
\hline Mastery-avoidance & 5.14 & 1.24 & -.917 & .777 & .77 \\
\hline $\begin{array}{l}\text { Performance- } \\
\text { approach }\end{array}$ & 4.79 & 1.40 & -.471 & -.383 & .72 \\
\hline $\begin{array}{l}\text { Performance- } \\
\text { avoidance }\end{array}$ & 4.35 & 1.60 & -.439 & -.634 & .76 \\
\hline $\begin{array}{l}\text { Sportspersonship } \\
\text { Perceived ability }\end{array}$ & 5.66 & .88 & -.899 & 2.079 & .87 \\
\hline
\end{tabular}


Table 1.

The mean experience of the participants were 7.55 years (age range $=$ $1-27$ years, $S D=5.34)$. The average for football players was 10.13 years $(S D=$ $4.6)$, for basketball players was 12.09 years $(S D=4.7)$, for handball players was 4.15 years $(S D=3.5)$, and for volleyball players was 4.05 years $(S D=3.1)$. The average chronological age for the professional athletes was 23.64 years $(S D=5.2)$ and for the amateurs 19.45 years $(S D=5.00)$ years. Ninety nine athletes $(24.3 \%)$ were professional while the remaining $308(75.7 \%)$ were amateur. Most of the participants (75.4\%) were unemployed, $14.3 \%$ and $3 \%$ employed in the private and public sector respectively, and $7.4 \%$ were entrepreneurs. Most of the participants (64.9\%) were competing in national leagues, and the remaining in local leagues (35.1\%).

\subsection{Validity of the Multidimensional Sportspersonship Orientation Scale}

Four models were tested to examine the factorial validity of MSOS; a 5-factor baseline measurement model, and a 5 -factor correlated model as proposed by Vallerand et al. (1997). Based on recommendations by Lemyre et al. (2002) on the inadequacy of negative approach toward the practice of sport to form a salient factor of the scale, two more 4-factor models were tested without the inclusion of negative approach toward the practice of sport subscale; a 4-factor baseline measurement model, and a 4-factor correlated model. The results of the CFA revealed that none of the 5-factor models and the 4-factor uncorrelated model showed excellent model fit. Only the 4-factor correlated model showed borderline but adequate model fit $(C F I=.90, R M S E A=.08)$ suggesting evidence on the factorial validity of a scale measuring four subscales. Accordingly, the sportspersonship orientations index was calculated by averaging the scores of the four subscales of this scale (Vallerand \& Losier 1994).

\subsection{Demographic characteristics, achievement goals, and sportspersonship orientations}

Achievement goals and the eight possible mediators (age, gender, education, level of participation, league, years of experience, and occupation) were mean centered. Next, linear regression analyses were performed to examine the unique effect of achievement goals on sportspersonship orientations. The results of the analyses indicated that mastery-approach, $F(1,400)=55.02, p<$ $.001, b=.34$, mastery-avoidance, $F(1,402)=77.57, p<.001, b=.40$, performance-approach goals, $F(1,399)=10.14, p<.001, b=.15$, and performance-avoidance goals, $F(1,400)=9.67, p<.001, b=.15$, were significant predictors of sportspersonship orientations. These results support the first criterion for moderation for all achievement goals.

To examine the moderating role of athletes' demographic characteristics in the achievement goal-sportspersonship orientations 
relationship, following Baron and Kenny's (1986) guidelines, the predictor variables included the demographic characteristics, achievement goals and an interaction term denoting a multiplicative association between these variables (i.e., achievement goals $\times$ demographic characteristic). A simple moderated effect emerges when the incremental variance explained by the interaction term is statistically significant, over and above the variance explained by the main effects of the predictor variables or, alternatively, if the Beta value of the interaction term is significant (Aiken \& West, 1991; Baron \& Kenny, 1986). In essence, the moderated regression analysis examines the hypothesis that the predictive effect of the interaction term will differ significantly from zero (null effect). Table 2 presents all results concerning the moderating role of athletes' demographic characteristics on sportspersonship.

\begin{tabular}{|c|c|c|c|c|c|}
\hline $\begin{array}{l}\text { Moderation } \\
\text { analysis }\end{array}$ & Step & Adj $R^{2}$ & $\mathbf{F}$ & B & $\mathbf{b}$ \\
\hline \multirow[t]{4}{*}{ Mastery approach } & & 26.9 & $9.51^{*}$ & & \\
\hline & Gender & & & .354 & .214 \\
\hline & Level of participation & & & .516 & .241 \\
\hline & Perceived ability & & & -.068 & -.148 \\
\hline \multirow[t]{2}{*}{ Mastery avoidance } & & 19.2 & $6.53^{*}$ & & \\
\hline & Level of participation & & & .272 & .163 \\
\hline \multirow{4}{*}{$\begin{array}{l}\text { Performance } \\
\text { approach }\end{array}$} & & 10.7 & $3.75^{*}$ & & \\
\hline & Years of experience & & & .265 & .156 \\
\hline & Occupation & & & -.138 & -.108 \\
\hline & Perceived ability & & & -.123 & -.118 \\
\hline
\end{tabular}

Table 2. Summary of hierarchical regression analyses testing for moderation effects.

The first set moderation analysis assessed the interaction between mastery-approach-demographic characteristics and sportspersonship orientations. Mastery-approach goals were entered at the first step and predicted $11 \%$ (Adj $R^{2}$ ) of the variance in sportspersonship orientations. Mean

${ }^{*} \mathrm{p}<0.01$, sets of moderation analyses correspond to those in the results section, only significant moderation effects are reported, the $B$ and $b$ values reflect those of the interaction terms 
centered demographic characteristics were entered at the second step and did not have significant effect on the variance predicted. The interaction terms (mastery approach goals $\times$ demographic characteristics) were entered at the final step of the analysis, and significantly increased the predicted variance, Adj $R^{2}$ change $=.16, p<.001$. The effect of mastery approach goals was retained significant, $B=.29, b=.34, p<.001$, while the effect of the interaction term of athletes' gender, $B=.35, b=.21, p<.001$, and level of participation, $B=.51, b=$ $.24, p<.001$ was significant.

The second moderation analysis assessed the interaction between mastery avoidance-demographic characteristics and sportspersonship orientations. Mastery avoidance goals predicted 16\% (Adj $\left.R^{2}\right)$ of the variance in sportspersonship orientations. The mean centered demographic characteristics entered at the second step improved the variance predicted, Adj $R^{2}$ change $=.03, p<.05$. The interaction terms (mastery avoidance goals $\times$ demographic characteristics) significantly increased the predicted variance, Adj $R^{2}$ change $=.03, p=.05$. The effect of mastery avoidance goals was still significant, $B=.25, b=.35, p<.001$, while the effect of the interaction term of athletes' level of participation, $B=.27, b=.16, p<.001$, was significant.

The third moderation analysis assessed the interaction between performance approach-demographic characteristics and sportspersonship orientations. Performance approach goals predicted 2\% (Adj $\left.R^{2}\right)$ of the variance in sportspersonship orientations. The mean centered demographic characteristics improved the variance predicted, Adj $R^{2}$ change $=.04, p<.05$. The interaction terms (performance approach goals $\times$ demographic characteristics) significantly increased the predicted variance, $A d j R^{2}$ change $=$ $.08, p<.001$. The effect of performance approach goals was still significant, $B=$ $.11, b=.17, p<.001$, while the effect of the interaction terms of athletes' years of experience, $B=.03, b=.26, p<.001$, and occupation, $B=-.10, b=-.13, p<$ .05 were significant.

Finally, the fourth moderation analysis assessed the interaction between performance avoidance-demographic characteristics and sportspersonship orientations. Performance avoidance goals predicted $2 \%$ (Adj $R^{2}$ ) of the variance in sportspersonship orientations. The mean centered demographic characteristics improved the variance predicted, $A d j R^{2}$ change $=$ $.05, p<.01$ ). The addition of the interaction terms (performance avoidance goals $\times$ demographic characteristics) in the third step did not increased significantly the predicted variance, Adj $R^{2}$ change $=.02, p=.001$.

\section{Discussion}

The aim of the present study was to examine the influence of achievement goals on sportspersonship orientations of team sport athletes and whether these relationships were moderated by athletes' demographic characteristics. 
The results of the analyses indicated that all achievement goals were significant predictors of sportspersonship orientations. Furthermore, demographic characteristics moderated several achievement goal sportspersonship relationships.

With respect to sportspersonship orientations scale, the results of the confirmatory factor analysis did not support the 5-factor structure proposed by Vallerand et al. (1997). Instead, similar to Lemyre et al. (2002) a 4-factor solution was confirmed. These findings are not identical with the previous use of MSOS with Greek high school students (Pavlopoulou et al. 2003) where the negative approach factor emerged as a valid dimension of the scale. It seems that the negative approach toward sport participation is a meaningful aspect of sportspersonship orientations when it is examined in school settings and may reflect views that students encompass as spectators and not necessarily as sporting participants. On the other hand, congruent with Lemyre et al. (2002), this construct was not found to be meaningful for competitive athletes. Cronbach's alphas supported the internal consistency of the scales for this 4factor solution, and the analysis of correlation provided evidence on the construct validity of the scale suggesting its use with Greek athletes.

With respect to the study's hypotheses, the results of the analyses provide partial support to the first hypothesis. All achievement goals revealed a positive effect on sportspersonship orientations. The findings pertaining to mastery goals are congruent with previous research indicating that task orientation is positively linked to sportspersonship orientations (Lemyre et al. 2002), and predict positively athletes' respect for opponents and respect for the game (Gano-Overway et al. 2005). This implies that, for an athlete to express moral competence during sport involvement, it is crucial to understand these activities as challenging and important to the self rather than as an opportunity to outperform others. This is further supported by the positive effect of mastery avoidance goals on sportspersonship orientations dimensions. These findings imply that athletes seeking personal improvement and mastery of the task at hand form positive sportspersonship orientations, even when they are concerned with not being able to improve themselves. It seems that the emphasis on the self is the core concept that leads to the formation of moral behavior in sports.

On the other hand, the positive, albeit low, prediction between sportspersonship orientations and performance goals (both approach and avoidance) contradicts previous evidence indicating that high ego orientation is negatively correlated with sportspersonship orientations, and positively with unsportsmanlike play and cheating (Duda et al. 1991; Lemyre et al. 2002). No clear explanations can be provided for such findings. A plausible explanation may lie on the fact that performance goals focus on perceptions of competence whereas ego orientation on perceptions of success. It seems that in the pursuit of competence (or avoidance of the demonstration of 
incompetence), even when it is conceptualized as superior or inferior ability compared to others, cheating is not an acceptable practice as it inherently implies low ability. On the other hand, in the pursuit of success cheating may be considered as an acceptable practice in order to win. If this is the case, performance oriented athletes, compared to ego oriented ones, may report high levels of sportspersonship orientations, which in fact don't interfere with their focus during sport involvement. Interestingly, these findings contradict prior research with Greek team sport athletes reporting a negative effect of performance goals on moral judgment (Mouratidou et al. 2012). A possible explanation might be that moral judgment competence is a more general construct of morality whereas sportspersonship orientations involve a more sport-specific concept. Hence, performance oriented athletes (approach and avoidance) endorse a less moral profile globally but when it comes to sports the demonstration of low morality is not evident, as it doesn't help them fulfill their goal for sport participation (i.e., demonstration of competence). Clearly more research is needed to substantiate the effect of performance goals on moral-related issues and the conceptualization of morality in the context of sport.

With respect to the moderating effect of demographic characteristics on the achievement goal - sportspersonship orientations relationship, the results indicated that athletes' gender and level of participation moderated the effect of mastery-approach goals on sportspersonship orientations. The effect of mastery approach goals on sportspersonship orientations was stronger for females and amateur athletes. With respect to gender, these findings are consistent with previous research evidence indicating that males adopt more often cheating, unsportsmanlike, and aggressive behaviors (Duda et al. 1991; Gardner \& Janelle 2002) and consider rule violating behavior as more acceptable compared to females (Gardner \& Janelle 2002). This is now evident even among athletes adopting mastery approach goals, the most adaptive goal pattern. These findings might be ascribed to gender stereotypes that create different social expectations concerning males' and females' social behavior; males are expected to be more aggressive than females (see also Conway et al. 2005).

The findings pertaining to the level of competition indicated that amateur athletes adopting mastery approach goals were expected to show a more positive sportspersonship orientations profile. Identical findings were also found regarding the mastery avoidance - sportspersonship orientations relationship. Again, the effect was stronger for amateur athletes. So far there is only scarce evidence on the role the athletes' league plays in the expression of morality. Mouratidou et al. (2012) reported on no moderating role of league in achievement goals - moral competence relationship. The findings of the present study imply that, even among athletes who focus on personal improvement, competition at professional levels may be detrimental to their 
moral behavior. These findings support previous evidence (Beller \& Stoll 1995; Mouratidou et al. 2007; Stephens 2001) indicating that professionalism is a significant reason for lowering an athlete's morality. The need for professional athletes to maintain high levels of performance attainments in order to obtain the associated rewards (e.g., higher contracts, publicity etc.) might result in a higher tendency to use illegitimate acts such as violating the rules, showing no respect for opponents, cheating etc. On the other hand, amateur athletes participating in sports merely for reasons such as the pleasure of the activity, socialization, improved physique and conditioning etc., and cheating, using illegitimate acts and showing immoral behaviors do not conform to these foci of sports participation. Hence, it seems that a more recreational sport setting facilitates the development of sportspersonship orientation even when athletes' focus for sport participation is personal improvement and progress and mastery of the tasks at hand.

The effect of performance approach goals on sportspersonship orientations was moderated by years of experience and occupation. This effect was stronger for more experienced athletes, public and private sector employees. With respect to years of experience, the findings of the present study are consistent to those reported in previous studies, which indicated that age affects athletes' moral functioning (Romand et al. 2009), sportspersonship (Shields et al. 2007), and prosocial and antisocial behaviors (Kavussanu et al. 2006). In addition, these findings are congruent with prior research including experience as an intervening characteristic, and supported its role in the formation of athletes' moral profile (Mouratidou et al. 2012) and their aggressive and/or assertive acts (Gardner \& Janelle 2002). Jointly these findings imply that more experienced athletes demonstrate a more moral profile even when adopting performance approach goals. In line with our findings on the effect of performance approach goals on sportspersonship orientations discussed above, it seems that experienced athletes are aware that by using immoral behaviors will not demonstrate higher competence. These findings might imply that morality is developed alongside with age and experience. Kohlberg's (1958) views on moral development support this assertion. More specifically, Kohlberg suggested that moral development is associated with cognitive development, and therefore it is expected that as the athletes' experience increases, the higher their moral competence will be.

Regarding occupation, the study's findings suggest that athletes who are servants and adopt performance approach goals are more prompt to show higher levels of sportspersonship orientations. So far, research investigating socioeconomic status has produced to contradictory findings showing neutral (Gardner \& Janelle 2002) or positive effect (Rutten et al. 2008) on moral behaviors. Although occupation does not necessarily reflect socioeconomic level, the findings of the present study support those of Rutten et al. (2008). Taking into consideration that public servants have a rather stable job, these 
findings imply that occupational stability might be associated with higher levels of sportspersonshsip orientations when performance approach goals are present. Clearly more research is needed to further examine the role of athletes' job and socioeconomic status in the formation of their sportspersonship orientations.

Interestingly, demographic characteristics had no moderation effect on the performance avoidance goals - sportspersonship orientations relationship. These findings indicate that athletes adopting a performanceavoidance orientation might endorse a high sportspersonship orientation during sport involvement, independently of their distinct demographic characteristics (such as age, gender, sport experience, level and league of sport participation, education, and occupation). Firstly, the positive effect of performance avoidance goals on sportspersonship orientations is in contrast with prior research suggesting that this goal type is the most maladaptive (Cury et al. 2003; Cury et al. 2006; Elliot \& McGregor 2001). This finding is difficult to interpret. A plausible explanation may lie on the fact that the focus of this goal is the avoidance of the demonstration of incompetence. Hence, athletes adopting this goal seem to be aware that endorsing unsportspersonship orientations and using illegitimate means, although it might result in winning and success, it will be interpreted as low competence. That is, these athletes are not capable enough and need to use such means to succeed. Secondly, our findings are consistent with Mouratidou et al. (2012), suggesting only limited moderating effect of the demographic characteristics on the performance avoidance - moral related variables. Clearly more research is needed concerning the role of performance-avoidance goals in the formation of morality.

Overall, the findings of the present study indicate that all achievement goals can influence athletes' sportspersonship orientation. Furthermore, this effect was moderated by several demographic characteristics, such as years of sport experience, gender, occupation, and level of participation. Although the present study has several innovative aspects (i.e., application of the $2 \times 2$ achievement goal approach, role of demographics), its sample was comprised of only team sports athletes. Therefore, the results cannot be generalized to individual sports with different structure (e.g., archery, swimming, athletics, etc.). For instance, in track and field athletics there are few leagues and the number of professional athletes is significant smaller compared to basketball and football. Furthermore, in basketball and football, athletes can compete successfully past the age of 40 , while this is not the case for athletics and other individual sports. This might differently affect the formation and demonstration of moral behavior, as experience was found to be a significant moderator. Therefore, the findings of the present study should be generalized to other sports with caution and future research should expand the findings of the present study into more sports. 
Another limitation of the present study is the cross-sectional design of the study. The results of the study do not describe cause and effect relationships, they are correlational in nature and they should be interpreted as such. Future research should also examine these relationships longitudinally (i.e., at the beginning, in the middle and at the end of the competitive season), and prior important competitions (i.e., Cup's finals, Final Four, etc). Further, future research should replicate present study with individual sport athletes, and athletes with a wider distribution on several demographic characteristics. Finally, the $2 \times 2$ achievement goal model is the most contemporary achievement goal approach and, as such, future research should more thoroughly test its effect on moral behavior (i.e., the effect of the multiple goal adoption on perceptions of sportspersonship orientations, moral competence, and actual moral behavior). In addition, the interaction of the four achievement goals, postulated in the $2 \times 2$ approach, would provide important information regarding the achievement goal profile and its association with sportspersonship orientations in sport settings.

\section{References}

Aiken, L. S. \& West, S. G. 1991. Multiple Regression: Testing and Interpreting Interactions. Newbury Park, CA: Sage.

Arnold, P. J. 1994. "Sport and Moral Education." Journal of Moral Education 23: 75-89.

Baron, R. M. \& Kenny, D. A. 1986. "The Moderator-Mediator Variable Distinction in Social Psychological Research: Conceptual, Strategic and Statistical Considerations." Journal of Personality and Social Psychology 51: 1173-1182.

Beller, J. M. \& Stoll, S. K. 1995. "Moral Reasoning of High School Student Athletes and General Students: An Empirical Study Versus Personal Testimony." Pediatric Exercise Science 7: 352-363.

Bentler, P. M. 2004. EQS: A Structural Equations Program. Encino, CA: Multivariate Software Inc.

Blair, S. 1985. "Professionalization of Attitude Toward Play in Children and Adults." Research Quarterly for Exercise and Sport 56: 82-83.

Conroy, D. E., Elliot, A. J., \& Hofer, S. M. 2003. "A 2x2 Achievement Goals Questionnaire for Sport." Journal of Sport and Exercise Psychology 25: 456-476.

Conway, M., Irannejad, S., \& Giannopoulos, C. 2005. "Status-Based Expectancies for Aggression, with Regard to Gender Differences in Aggression in Social Psychological Research." Aggressive Behavior 31: 381-398.

Corrion K., d'Arripe-Longueville F., Chalabaev A., Schiano-Lomoriello S., Roussel P., \& Cury F. 2010. "Effect of Implicit Theories on Judgment of 
Cheating Acceptability in Physical Education. The Mediating Role of Achievement Goals." Journal of Sport Sciences 28(8): 909-919.

Cury, F., Da Fonséca, D., Rufo, M., Peres, C., \& Sarrazin, P. 2003. "The Trichotomous Model and Investment in Learning to Prepare for a Sport Test: A Mediational Analysis." British Journal of Educational Psychology 73: 529-543.

Cury, F., Elliot, A., Da Fonseca, D., \& Moller, A. C. 2006. "The Social Cognitive Model of Achievement Motivation and the $2 \times 2$ Achievement Goal Framework." Journal of Personality and Social Psychology 90: 666-679.

Duda, J. L., Olson, L. K., \& Templin, T. J. 1991. "The Relationship of Task and Ego Orientation to Sportsmanship Attitudes and the Perceived Legitimacy of Injurious Acts." Research Quarterly for Exercise and Sport 62: 79-87.

Elliot, A. J. 1997. "Integrating the «Classic» and «Contemporary» Approaches to Achievement Motivation: A Hierarchical Model of Approach and Avoidance Achievement Motivation." In: Maehr, M. L. \& Pintrich, P. R. (Eds.) Advances in Motivation and Achievement. Vol. 10. Greenwich, CT: JAI Press: 143-179.

Elliot, A. J. \& McGregor, H. A. 2001. "A 2x2 Achievement Goal Framework." Journal of Personality and Social Psychology, 80: 501-519.

Frazier, P. A., Tix, A. P., \& Barron, K. E. 2004. "Testing Moderator and Mediator Effects in Counseling Psychology Research." Journal of Counseling Psychology 51: 115-134.

Fry, M. D. \& Newton, M. 2003. "Application of Achievement Goal Theory in an Urban Youth Tennis Setting." Journal of Applied Sport Psychology 15: 50-67.

Gano-Overway, L. A., Guivernau, M., Magyar, T. M., Waldron, J. J., \& Ewing, M. E. 2005. "Achievement Goal Perspectives, Perceptions of the Motivational Climate, and Sportspersonship: Individual and Team Effects." Psychology of Sport \& Exercise 6(2): 215-232.

Gardner, R. E. \& Janelle, C. M. 2002. "Legitimacy Judgments of Perceived Aggression and Assertion by Contact and Non-Contact Sport Participants." International Journal of Sport Psychology 33: 290-306.

Gibbons, S. L., Ebbeck, V., \& Weiss, M. R. 1995. "Fair Play for Kids: Effects on the Moral Development of Children in Physical Education." Research Quarterly for Exercise and Sport 3: 247-255.

Guivernau, M. \& Duda, J. L. 2002. "Moral Atmosphere and Athletic Tendencies in Young Soccer Players." Journal of Moral Education 31: 67-85.

Hu, L. \& Bentler, P. M. 1999. "Cutoff Criteria for Fit Indexes in Covariance Structure Analysis: Conventional Criteria Versus New Alternatives." Structural Equation Modeling 6: 1-55.

Karamavrou, S., Mouratidou, K., Vlachopoulos, S., \& Christofidi, Ch. 2004. "The Representation of Moral Maturity Level Through Stage Preference: A 
Comparative Study in Higher Educational Level." Hellenic Journal of Sport Psychology 15: 47-60.

Kavussanu, M. \& Roberts, C. G. 2001. "Moral Functioning in Sport: An Achievement Goal Perspective." Journal of Sport \& Exercise Psychology 23: 37-54.

Kavussanu, M., Seal, A. R., \& Phillips, D. R. 2006. "Observed Prosocial and Antisocial Behaviors in Male Soccer Teams: Age Differences Across Adolescence and the Role of Motivational Variables." Journal of Applied Sport Psychology 18: 326-344.

Kohlberg, L. 1958. The Development of Modes of Moral Thinking and Choice in the Zears 10 to 16. Unpublished doctoral dissertation. Chicago: University of Chicago, Il.

Lemyre, P. N., Roberts, C. G., \& Ommundsen, Y. 2002. "Achievement Goal Orientations, Perceived Ability and Sportspersonship in Youth Soccer." Journal of Applied Sport Psychology 14: 120-136.

Mouratidou, K., Barkoukis, V., \& Rizos, S. 2012. "Achievement Goals and Moral Competence in Sport: Examining the Moderating Role of Demographic Characteristics." European Psychologist 17: 34-43.

Mouratidou, K., Chatzopoulos, D., \& Karamavrou, S. 2007. "Moral Development in Sport Context: Utopia or Reality?” Hellenic Journal of Psychology 4: 163-184.

Nicholls, J. 1989. The Competitive Ethos and Democratic Education. Cambridge, MA: Harvard University Press.

Pavlopoulou, E., Goniadou, S., Zaxariadis, P., \& Tsorbatzoudis, H. 2003. "The Role of Motivation to Sportsmanship in Physical Education and Sport." Physical Education \& Sport 48: 60-72.

Romand, P., Pantaleon, N., \& Cabagno, G. 2009. "Age Differences in Individuals' Cognitive and Behavioral Moral Functioning Responses in Male Soccer Teams." Journal of Applied Sport Psychology 21: 49-63.

Rutten, E. A., Dekovic, M., Stams, G. J., Schuengel, C., Hoeksma, J. B., \& Biesta, G. J. 2008. "On- and Off-Field Antisocial and Prosocial Behavior in Adolescent Soccer Players: A Multilevel Study". Journal of Adolescence 31: 371-387.

Sage, L., \& Kavussanou, M. 2007. "The effects of Goal Involvement on Moral Behavior Experimentally Manipulated Competitive Setting". Journal of Sport \& Exercise Psychology 29: 190-207.

Shields, D. L. \& Bredemeier, B. J. 1995. Character Development and Physical Activity. Champaign, IL: Human Kinetics.

Shields, D. L., LaVoi, N. M., Bredemeier, B. L., \& Power, C. F. 2007. "Predictors of Poor Sportspersonship in Youth Sports: An Examination of Personal Attitudes and Social Influences." Journal of Sport \& Exercise Psychology 29: 747-762. 
Stephens, D. E. 2001. "Predictors of Aggressive Tendencies in Girls' Basketball: An Examination of Beginning and Advanced Participants in a Summer Skills Camp." Research Quarterly for Exercise and Sport 3: 257-266.

Treasure, D. C., Carpenter, P. J., \& Power, K. T. 2000. "Relationship Between Achievement Goal Orientations and the Perceived Purposes of Playing Rugby Union for Professional and Amateur Players." Journal of Sport Sciences 18: 571-577.

Vallerand, R. J., Briere, N. M., Blanchard, C., \& Provencer, P. 1997. “Development and Validation of the Multidimensional Sportspersonship Orientations Scale." Journal of Sport and Exercise Psychology 19: 197-206.

Vallerand, R. J. \& Losier, G. F. 1994. "Self-Determined Motivation and Sportsmanship Orientations: An Assessment of Their Temporal Relationship." Journal of Sport and Exercise Psychology 16: 229-245. 
Vassilis Barkoukis (Aristotle University of Thessaloniki)

Katerina Mouratidou (Aristotle University of Thessaloniki)

\title{
Achievement Goals and Sportspersonship Orientations in Team Sports. The Moderating Role of Demographic Characteristics
}

\begin{abstract}
The present study investigated whether achievement goals have differential effect on sportspersonship orientations in competitive sport and the moderating role of several demographic characteristics. Participants were 407 team sport athletes. The athletes completed a questionnaire including measures of achievement goals, sportspersonship orientations and demographic characteristics. The results of the analyses indicated that all achievement goals were significant predictors of sportspersonship orientations. Furthermore, demographic characteristics moderated several achievement goals - sportspersonship orientations relationships. These findings provide insightful information on the application of the $2 \times 2$ achievement goal approach in sports and the role of athletes' demographic characteristics.
\end{abstract}

Key words: sportsmanship, morality, achievement goals, demographic characteristics.

Ethics in Progress (ISSN 2084-9257). Vol. 6 (2015). No. 1, pp. 74-92.

doi: 10.14746/eip.2015.2.6 